Journal of Engineering and Applied Sciences 15 (2): 529-534, 2020

ISSN: 1816-949X

(C) Medwell Journals, 2020

\title{
Influence of Transformational Leadership Style and Organizational Culture to Organizational Citizenship Behavior and Employee's Performance in Mothers and Children Hospitals in East Java
}

\author{
${ }^{1}$ Mamik, ${ }^{1}$ Sari Luthfiyah, ${ }^{2}$ Ratifah and ${ }^{1}$ Tarini Ika Pipit Cahyani \\ ${ }^{1}$ Health Polytechnic of Surabaya, Surabaya, Indonesia \\ ${ }^{2}$ Health Polytechnic of Semarang, Semarang, Indonesia
}

\begin{abstract}
This study aims to test and analyze the influence of transformational leadership style and organizational culture to Organizational Citizenship Behavior (OCB) and employee's performance in mothers and children hospitals in East Java. The research samples are 89, i.e., 89 nurses and midwives who work in 3 mothers and children hospitals in East Java. The sampling technique uses population study. The analysis data method used is path analysis. The study results conclude that the transformational leadership style significantly influences OCB; the organizational culture significantly influences $\mathrm{OCB}$, the transformational leadership significantly influences employee's performance, the organizational culture insignificantly influences employee's performance and OCB significantly influences nurse's performance in mothers and child hospitals in East Java.
\end{abstract}

Key words: Transformational leadership style, organizational culture, organizational citizenship behavior, employee's performance, performance, significantly

\section{INTRODUCTION}

Mothers and children hospitals have important roles in the world of health, both in big cities and small cities. They are able to provide best services for all society and to give special offers for outpatient and inpatient services, especially, for mothers and children. Mothers and children hospital's success relies on their human resources. One of them is the role of nurses who provide health services to patients both mothers and children. Nurses must have ethics by being polite, always smiling and being sympathetic. With good ethics, a nurse is expected to be able to establish a more intimate relationship with the patients. Attitudes, behaviors, responsibilities and cleverness of the nurses in working can be set as benchmarks of nurse's performance. Many factors influence nurse's performance levels theoretically and empirically, i.e., transformational leadership style, organizational culture and Organizational Citizenship Behavior (OCB). Therefore, this research tries to analyze the influence of transformational leadership style and organizational culture to OCB and employee's performance, especially, nurses and midwives in mothers and children hospitals in East Java.

\section{Literature review}

Transformational leadership style: It is defines leadership style as someone's ability or style to influence other people. Transformational leaders changes the follower's awareness of problems by helping them to face past problems with new ways and they are able to stimulate, generate and inspire the followers to take extra efforts to achieve group goals. Jung et al. (2008) state that leaders with idealized influence demonstrate heightened concerns and cognizance of follower's needs and generate a sense of shared risk-taking. Cummings et al. (2010) observed that regardless of style, "leaders who practiced relational and transformational styles had better quality outcomes than those who demonstrated autocracy".

Organizational culture: Schein (2012) states that organizational culture is a group of basic assumptions. Organizational culture functions to give directions to organization members about what to watch out, the meaning of something to achieve, how about the reaction and action in certain situations. Understanding and managing organizational culture are not only directed to find an explanation about organization's success phenomena but also can be used to develop organization to be more effective.

Organizational Citizenship Behavior (OCB): Organ et al. (2006) defines OCB as a behavior which is an individual choice and initiative; it is not related to organization formal reward system but in aggregate it raises organization effectiveness. In other words, Organizational Citizenship Behavior (OCB) is an employee's behavior voluntarily, not a forced behavior to things that promote the interests of the company. 


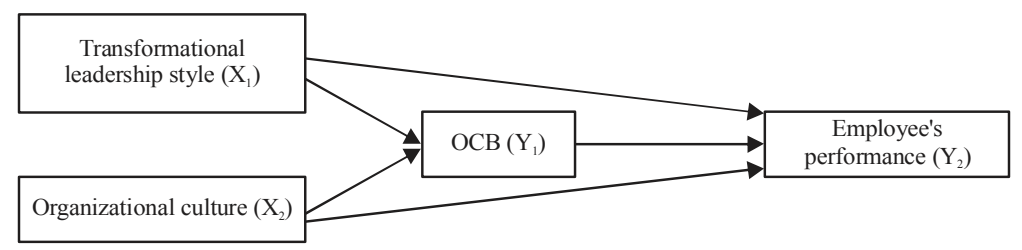

Fig. 1: Conceptual framework

Lambert defines OCB as behavior that goes beyond the basic requirements of the job is to a large extent discretionary and is of benefit to the organization. Organizational Citizenship Behaviour (OCB) also can defined as the organizational activities that the employees engage in voluntarily without the expectation to get any rewards (Lewis, 2010).

Employee's performance: Employee's performance is employee's levels to achieve work requirements. Indicators to measure employee's performance are work quantity, work quality, honesty, adherence, initiative and intelligence.

Conceptual framework and hypothesis: Figure 1 shows the transformational leadership style has influences to OCB. The relationship is explained by Malik et al. (2016) who shows that there is a positive strong relationship between leadership style and OCB. Leadership style significantly contributes in the increase of OCB. Thus, the hypothesis is as follows:

$\mathrm{H}_{1}$ : transformational leadership style significantly influences the organizational citizenship behavior of employees in mothers and children hospitals in East Java

Organizational culture influences OCB. The relationship is explained by Badawy et al. (2016) who shows that there is a positive correlation among four types of organizational culture, work satisfaction and OCB. Thus, the hypothesis is as follows:

$\mathrm{H}_{2}$ : organizational culture influences significantly to organizational citizenship behavior of the employees in mothers and children hospitals in East Java

Transformational leadership style influences employee's performance. The relationship is explained which show that simultaneously the influence of leadership style which consists of autocratic, democratic and free control to employee's performance is significant, also Mohiuddin (2017) explains that the appropriate leadership will be able to increase employee's performance. Therefore, the hypothesis is as follows:
$\mathrm{H}_{3}$ : transformational leadership style influences significantly to employee's performance in mothers and children hospitals in East Java

Organizational performance influences employee's performance. The relationship is explained by Awadh and Saad (2013) who show that a strong culture of an organization based on manager and leader helps in increasing performance level. Thus, the hypothesis is as follows:

$\mathrm{H}_{4}$ : transformational leadership style influences significantly to employee's performance in mothers and children hospital in East Java

The OCB influences employee's performance. The relationship is explained by Al-Mahasneh (2015), who concludes that Organizational Citizenship Behavior (OCB) influences positively to employee's performance in Greater Amman Municipality. Therefore, the hypothesis is as follows:

$\mathrm{H}_{5}$ : OCB influences significantly to employee's performance in mothers and children hospitals in East Java

\section{MATERIALS AND METHODS}

This is an explanatory research which further will analyze causal relations among variables by hypothesis test set previously. The population of this research is all nurses and midwives who work in 3 mothers and children hospitals in East Java, i.e., Lamongan, Malang and Gresik, that is 89 nurses. The sample of this research is 89 employees in mother and children hospitals. The sampling technique is population study. Analysis data method used is path analysis with SPSS Version 22.0 program.

\section{RESULTS AND DISCUSSION}

Result of validity test shows that all indicators of transformational leadership variable, organizational culture variable, organizational citizenship behavior variable and employee's performance have significant correlation result smaller than 0.05 (sig. $<0.05$ ), so, it is stated that all indicators are valid and can be further analyzed. 
Result of reliability test shows coefficient score of Alpha cronbach of each research variable is more than 0.6 (Alpha cronbach $>0.6$ ) so, it can be concluded that the variables used or investigated, namely transformational leadership style, organizational culture, organizational citizenship behavior and employee's performance are reliable to be further analyzed. Path analysis results are as follows:

$$
\begin{aligned}
& Y_{1}=0.683+0.610 X_{1}+0.318 X_{2} \\
& Y_{2}=0.627+0.258 X_{1}+0.718 Y_{1}
\end{aligned}
$$

Influence of transformational leadership style to OCB: According to the results of descriptive analysis of the transformational leadership style variable, it shows that in average transformational leadership style in mother and children hospitals in East Java is good with average score (mean) of transformational leadership style variable 3.803. This means that respondents give good rating to the transformational leadership style in mothers and children hospitals in East Java.

These research results which show that transformational leadership style significantly influences OCB of employees in mother and children hospitals in East Java, empirically support by Malik et al. (2016) research results which conclude that there is a strong and positive relationship between leadership style and OCB, leadership style significantly contributes to the OCB enhancement, the democratic leadership style stimulates more OCB for employees. Another research by Jiang et al. (2017), Nasra and Heilbrunn (2016) also have the same result. The study from Nasra and Heilbrun (2016) indicated a direct effect between transformational leadership and OCB. It is explain that transformational leadership did predict Organizational Citizenship Behaviors (OCB). Malik et al. (2016) explain in their study that leadership styles significantly contribute to increase or augment the organizational citizenship behavior and it means the transformational leadership styles related or associated positively with OCB that in lines with Saeed and Ahmad (2012) and Wang et al. (2011).

Influence of organizational culture and OCB: According to the results of descriptive analysis of the organizational culture variable, it shows that in average organizational culture in mother and children hospitals in East Java is good with average score (mean) of organizational culture variable 3.447 . This means that respondents give good rating to the organizational culture in mothers and children hospitals in East Java.
These research results which show that organizational culture significantly influences OCB of employees in mother and children hospitals in East Java, empirically support by Mohanty and Rath (2012), Ariyani et al. (2017), Carbajal (2006), Yaseen et al. (2015), El Badawy et al (2017) and Teh et al. (2012) that there is a positive correlation between Organizational Culture and OCB. Badawy et al. (2016) also support with the research results which conclude rhere is a positive correlation between four types of organizational culture, work satisfaction and $\mathrm{OCB}$, work satisfaction mediate the relationship between organizational culture and OCB but the effect of mediation is weak. Another study also had a result that support this study. It is explain that organizational culture had an indirect effect on employee performance through OCB. Research findings by Muhdar and Rahma (2015), indicate that organizational culture impact on OCB positively and significantly. Mohant and Rath (2012) explain in their study that the organizational culture can predict the prevalent of the organizational citizenship behaviors.

Influence of transformational leadership style to employee's performance: According to the results of descriptive analysis of the employee's performance variable, it shows that in average employee's performance in mother and children hospitals in East Java is high with average score (mean) of employee's performance variable 4.264. This means that respondents judge that the performance of employees is good or very high.

These research results which show that transformational leadership style significantly influences employee.s performance of employees in mother and children hospitals in East Java, empirically support Mohiuddin (2017). One of research results is simultaneously shows that the influence of leadership style which consists of autocratic, democratic and free control, together to the employee's performance is significant. Meanwhile, Mohiuddin (2017) research results conclude a proof of literature which shows that transformational leadership approach has a more profitable result in the worker execution than transactional where the concentration is in the leader's hands. The finding also in line with Liao and Chuang (2007), Nemanich and Keller (2007), McColl-Kennedy and Anderson (2002), Salanova et al. (2011), Vigoda-Gadot (2007), Walumbwa et al. (2008) and Wang et al. (2011). The effect of transformational leadership on rated performance was also mediated by the interaction of identification and means efficacy as well as partially mediated by the interaction of self-efficacy and means efficacy. The point is the proper leadership style will be able to improve employee's performance (Walumbwa et al., 2008). There is direct relationship between leadership and performance (in role and OCB) (Vigoda-Gadot, 2007). 
Influence of organizational culture to employee's performance: These research results which show that organizational culture does not significantly influence OCB employee's performance in mother and children hospitals in East Java, empirically does not support Awadh and Saad (2013) research results which conclude that a strong culture of an organization based on manager and leader helps in improving performance level. Organizational culture influences employee's performance. This finding also opposite with Lee and $\mathrm{Yu}$ (2004), Jacobs et al. (2013) and Xenikou and Simosi (2006) research. The organizational culture was found to impact a variety of organizational processes and performance (Lee and $\mathrm{Yu}, 2004)$. It varies across hospitals and over time and this variation is at least in part associated in consistent and predictable ways with a variety of organizational characteristics and routine measures of performance (Jacobs et al., 2013). Moreover a path analysis showed that the achievement and adaptive cultural orientations had a direct effect on performance (Xenikou and Simosi, 2006).

Influence of organizational citizenship behavior to employee's performance: These research results which show that OCB significantly influences employee's performance of employees in mother and children hospitals in East Java, empirically support AlMahasneh (2015) research results which that OCB positively influences employee's performance in Greater Oman Municipality. Bommer et al. (2007) found that high individual-level OCB yielded greater significant increases in job performance ratings. Moreover this research finding supported the previous research done by Bell (2004) that argued there is a direct positive relation between the OCB of the employee who is directly interact with the customer and the customer perception towards the service quality performances. Another study done by Castro et al. (2004) is also proved the influence of OCB to the perception of customer regarding the service quality performances. Podsakoff et al. (2009) was also proved OCB positively influenced job performance. The OCB has positive effect on the supervisor's evaluation of the individual performance, both directly and indirectly, through the impact OCB had on the supervisor's fondness of individual (Vilela et al., 2008). This means that the perception of employees to OCB has positive and significant influence to employee's performance. The OCB affects volume and quality of work, relationship between co-workers as the dependent variables and relationship between staffs and their superintendent. or it may be due to more work-related reasons such as the manager's belief that OCB plays a significant role in the organization's overall success or perception of OCB as a form of employee commitment due to its voluntary nature (Organ et al., 2006).

\section{CONCLUSION}

Based on the research results analysis of the influence of transformational leadership style and organizational culture to OCB and employee's performance, it can be concluded that: the transformational leadership style significantly influences OCB, the transformational leadership influences significantly to employee's performance, the organizational culture insignificantly influences employee's performance, OCB significantly influences employee's performance, transformational leadership style and organization culture indirectly influences employees performance significantly via OCB, $\mathrm{OCB}$ is an intervening variable which is able to strengthen the relationship or influence of transformational leader and organizational culture to nurse's performance in mothers and children hospitals in East Java.

\section{IMPLICATIONS}

Based on the above conclusion, it is suggested to the mothers and children hospitals in East Java for always strengthen OCB spirit of the nurses for instance by motivating and supporting nurse's nature of helping, raising nursing self-awareness, increasing nurse's sportsmanship, raising mutual respect and also giving responsibility and authority to the employees namely nurses and midwives for improving the job quality.

\section{REFERENCES}

Al-Mahasneh, M.A., 2015. The impact of organizational citizenship behavior on job performance at greater Amman Municipality. Eur. J. Bus. Manage., 7: 108-118.

Ariyani, I., S. Haerani, H. Maupa and M.I. Taba, 2017. The influence of organizational culture, work motivation and working climate on the performance of nurses through job satisfaction, organizational commitment and organizational citizenship behavior in the private hospitals in Jakarta, Indonesia. Sci. Res. J., 4: 15-29.

Awadh, A.M. and A.M. Saad, 2013. Impact of organizational culture on employee performance. Int. Rev. Manage. Bus. Res., 2: 168-175.

Badawy, T.A.E., M.M. Kamel and M.M. Magdy, 2016. Exploring the relationship between organizational culture, job satisfaction and organizational citizenship behavior. Intl. J. Hum. Resour. Stud., 6: 20-33.

Bell, S.J., 2004. Raising the bar of service quality: The role of salesperson-organizational relationship, organozational citizenship behavior. Bulent Menguc Department Manage. Univ. Melbourne, 1: 1-22. 
Bommer, W.H., E.C. Dierdorff and R.S. Rubin, 2007. Does prevalence mitigate relevance? The moderating effect of group-level OCB on employee performance. Acad. Manage. J., 50: 1481-1494.

Carbajal, J.M., 2006. Influence of organizational culture on the relationship between psychological contracts and organizational citizenship behavior. Master Thesis, Air Force Institute of Technology, Kaduna, Nigeria.

Castro, C.B., E.M. Armario and D.M. Ruiz, 2004. The influence of employee organizational citizenship behavior on customer loyalty. Int. J. Serv. Ind. Manage., 15: 27-53.

Cummings, G.G., W.K. Midodzi, C.A. Wong and C.A. Estabrooks, 2010. The contribution of hospital nursing leadership styles to 30-day patient mortality. Nurs. Res., 59: 331-339.

El Badawy, T.A., J.C. Trujillo-Reyes and M.M. Magdy, 2017. Exploring the relationship between organizational culture, organizational citizenship behavior and job satisfaction: A comparative study between Egypt and Mexico. Intl. J. Manage. Administrative Sci., 4: 1-15.

Jacobs, R., R. Mannion, H.T.O. Davies, S. Harrison and F. Konteh et al., 2013. The relationship between organizational culture and performance in acute hospitals. Soc. Sci. Med., 76: 115-125.

Jiang, W., X. Zhao and J. Ni, 2017. The impact of transformational leadership on employee sustainable performance: The mediating role of organizational citizenship behavior. Sustainability, Vol. 9, 10.3390/su9091567.

Jung, D.D., A. Wu and C.W. Chow, 2008. Towards understanding the direct and indirect effects of CEOs transformational leadership on firm innovation. Leadersh. Q., 19: 582-594.

Lee, S.K.J. and K. Yu, 2004. Corporate culture and organizational performance. J. Managerial Psychol., 19: 340-359.

Lewis, D.B., 2010. A Global Approach to Public Interest Disclosure: What Can We Learn from Existing Whistleblowing Legislation and Research. Edward Elgar Publishing, Cheltenham, UK., ISBN: 978-1-84844-899-5, Pages: 113.

Liao, H. and A. Chuang, 2007. Transforming service employees and climate: A multilevel, multisource examination of transformational leadership in building long-term service relationships. J. Applied Psychol., 92: 1006-1019.

Malik, S.Z., M. Saleem and R. Naeem, 2016. Effect of leadership styles on organizational citizenship behaviour in employees of telecom sector in Pakistan. Pak. Econ. Soc. Rev., 54: 385-406.

McColl-Kennedy, J.R. and R.D. Anderson, 2002. Impact of leadership style and emotions on subordinate performance. Leadersh. Q., 13: 545-559.
Mohanty, J. and B.P. Rath, 2012. Influence of organizational culture on organizational citizenship behavior: A three-sector study. Global J. Bus. Res., 6: 65-76.

Mohiuddin, Z.A., 2017. Influence of leadership style on employees performance: Evidence from literatures. J. Marketing Manage., 8: 18-30.

Muhdar, H.M. and S.T. Rahma, 2015. The influence of spiritual intelligence, leadership and organizational culture on organizational citizenship behavior: A study to Islamic bank in Makassar City. AlUlum, 15: $135-156$.

Nasra, M.A. and S. Heilbrunn, 2016. Transformational leadership and organizational citizenship behavior in the Arab educational system in Israel: The impact of trust and job satisfaction. Educ. Manage. Administration Leadersh., 44: 380-396.

Nemanich, L.A. and R.T. Keller, 2007. Transformational leadership in an acquisition: A field study of employees. Leadersh. Q., 18: 49-68.

Organ, D.W., P.M. Podsakoff and S.B. MacKenzie, 2006. Organizational Citizenship Behavior: Its Nature, Antecedents and Consequences. SAGE Publications Inc., California, USA., ISBN-13: 978-0761929963, Pages: 360.

Podsakoff, N.P., S.W. Whiting, P.M. Podsakoff and B.D. Blume, 2009. Individual-and organizationallevel consequences of organizational citizenship behaviors: A meta-analysis. J. Applied Psychol., 94: 122-141.

Saeed, A. and S. Ahmad, 2012. Perceived transformational leadership style and organizational citizenship behavior: A case study of administrative staff of University of the Punjab. Eur. J. Bus. Manage., 4: 150-158.

Salanova, M., L. Lorente, M.J. Chambel and I.M. Martinez, 2011. Linking transformational leadership to nurses extra role performance: The mediating role of self efficacy and work engagement. J. Adv. Nurs., 67: 2256-2266.

Schein, E.H., 2012. Corporate Culture and Organizational Effectiveness. John Wiley \& Sons, New York, USA.

Teh, C.J., A. Boerhannoeddin and A. Ismail, 2012. Organizational culture and performance appraisal process: Effect on organizational citizenship behavior. Asian Bus. Manage., 11: 471-484.

Vigoda-Gadot, E., 2007. Leadership style, organizational politics and employees' performance: An empirical examination of two competing models. Personnel Rev., 36: 661-683.

Vilela, B.B., J.A.V. GonzAlez and P.F. Ferin, 2008. Person-organization fit, OCB and performance appraisal: Evidence from matched supervisorsalesperson data set in a Spanish context. Ind. Market. Manage., 37: 1005-1019. 
Walumbwa, F.O., B.J. Avolio and W. Zhu, 2008. How transformational leadership weaves its influence on individual job performance: The role of identification and efficacy beliefs. Personnel Psychol., 61: 793-825.

Wang, G., I.S. Oh, S.H. Courtright and A.E. Colbert, 2011. Transformational leadership and performance across criteria and levels: A meta-analytic review of 25 years of research. Group Organiz. Manage., 36: 223-270.
Xenikou, A. and M. Simosi, 2006. Organizational culture and transformational leadership as predictors of business unit performance. J. Managerial Psychol., 21: $566-579$.

Yaseen, A., M. Liquat, Ibn-e-Hassan and M. Hassan, 2015. Impact of organizational culture and social influence on organizational citizenship behaviour with mediating effect of interactional justice. Sci. Intl., 27: 2443-2450. 